\title{
On the accuracy of fragment size measurement by image analysis in combination with some distribution functions
}

\author{
By \\ J. A. Sanchidrián ${ }^{1}$, P. Segarra ${ }^{1}$, F. Ouchterlony ${ }^{2}$, L. M. López ${ }^{1}$ \\ ${ }^{1}$ Universidad Politécnica de Madrid, E.T.S.I. Minas, Madrid, Spain \\ ${ }^{2}$ Swebrec, Luleå University of Technology, Stockholm, Sweden
}

Received June 24 2006; Accepted November 14 2007; Published online 31 July 2008

(C) Springer-Verlag 2008

\begin{abstract}
Summary
Size distributions of fragments of crushed rock in conveyor belts and of blasted rock in a muckpile obtained by sieving are compared with the size distributions obtained by digital image analysis of photographs of the same materials taken on-site. Several calculation methods are tested, based on the raw distribution of fragment areas and on the volume-transformed ones. The influence of the calibration of the system on the results and the performance of the system in a non-calibrated mode are evaluated. The capacity of some distributions (Rosin-Rammler, Swebrec and lognormal) to fit the data in the coarse region (where particles can be delineated, i.e. discriminated individually) and to extrapolate to the non-delineated fines (where particles cannot be outlined and their contour delineated) is assessed. The error between the sizes measured and the sizes of the reference distributions (determined by sieving) increases from the coarse to the fines region. The maximum error at a given size depends primarily on its value relative to the fines cut-off (FCO) of the image analysis. In general, at sizes greater than the FCO, where the system is able to delineate fragments reliably, both volume and surface-based, calibrated, calculations can determine the sizes with maximum error expectancy of about $30 \%$. Below the FCO, only the calibrated, volume calculation maintains a maximum error of $30 \%$, down to sizes of about one fourth the FCO, rapidly increasing for smaller sizes. Where the calibration is done based on data above the FCO, errors can be large below this point, in excess of $80 \%$ at sizes half the FCO. In the fines range (sizes smaller than 0.2 times the FCO) the maximum errors can be close to or greater than $100 \%$ for most of the calculations and function fittings. Of the distributions tested, all of them are acceptable at sizes above the FCO; below that, the Swebrec function seems to adapt better towards the fines than the Rosin-Rammler and lognormal.
\end{abstract}

Keywords: Rock blasting, fragmentation, image analysis, size distribution, Rosin-Rammler, lognormal, Swebrec.

Correspondence: José A. Sanchidrián, Universidad Politécnica de Madrid, E.T.S.I. Minas, Rios Rosas 21, 28003 Madrid, Spain

e-mail: ja.sanchidrian@upm.es 


\section{J. A. Sanchidrián et al.}

\section{Introduction}

Digital image analysis is a powerful means for assessing the size distribution of rock fragmented by blasting. For obvious reasons, sieving is generally unfeasible in a production scenario. Belt scale readings at different locations of the processing plant and production data of the various size fractions can provide relevant data on the overall output of the operation (blasting and processing), but their relation with blasting is limited. Other indicators, such as energy consumption or throughput in the primary crusher serve as indirect estimators of fragmentation, e.g. the $80 \%$ passing size. Where the aim is to assess the size distribution, or at least some characteristic size of the blasted rock for blasting control purposes, digital image analysis is at present the only practical tool. However, despite of being used in mines and quarries worldwide, the image analysis methods have a variety of problems, namely:

(i) Proper delineation of particles. The delineation algorithms of the fragments incur certain errors - mainly disintegration of large fragments in the image and fusion of small ones - that must be corrected manually to have reliable fragmentation results, especially if the amount of fines is of interest. The manual editing of the images, in turn, causes errors due to the subjectivity of the task. These are generally large at small particles sizes, but limited at sizes greater than the optical resolution of the system (Sanchidrián et al., 2006).

(ii) Use of unfolding solutions to transform surface measurements of particles into volume values. Volume calculations involve assumptions about particle shape, overlap between fragments and estimation of non-photographed particles at depth (Cunningham, 1996; Split Engineering, 2001; Ouchterlony, 2003a). The latter is crucial when there is segregation, as occurs in images of low uniformity material on trucks. Correction factors are applied to the original fragment sizes (Girdner et al., 1996), number of particles (Maerz, 1996), amount of fines (Kemeny et al., 1999; Split Engineering, 2001), or to the parameters of a distribution function fitting the measured values (Maerz and Zhou, 2000). The correction factors, however, may not apply to situations other than those from which they were derived. The "excessive" treatment of data could be reduced by leaving aside the volume extrapolations, as Cunningham (1996) advises and the Powersieve ${ }^{\mathrm{TM}}$ system does (Chung and Noy, 1996). Surface-based size distributions are borne on the premise that the errors in the third dimension are constant at least for the same rock type sampled in the same way.

(iii) The resolution of the image systems is limited to 1-1.5 orders of magnitude in size, or even smaller, while normal muckpile and crushed fragment size distributions cover 2 or 3 orders of magnitude for a percentage of material of 90-95\%. The resolution problem is solved assuming a specific size distribution for the fines after their amount has been assessed from their surface area in the image (Kemeny et al., 1999; Split Engineering, 2001). In principle, by fines it is meant the particles smaller than the resolution of the camera and/or the delineation system, though the exact definition of the term may vary from one system to another. The distribution functions used for the fines are the Weibull-Rosin-Rammler (RR):

$$
P(x)=1-e^{-\ln 2\left(\frac{x}{x_{50}}\right)^{n}}
$$


and the Gaudin-Schuhmann (the RR asymptote at small size, a straight line in $\log -\log$ coordinates):

$$
P(x)=\left(\frac{x}{x_{\max }}\right)^{m}
$$

where $P(x)$ in both functions is the volume fraction of material smaller than size $x$, or fraction passing a mesh of size $x$. The parameters (two in both functions) are derived from two points near the optical resolution of the image. An alternative procedure (Maerz and Zhou, 2000) assumes a RR distribution for all the fragments' size range and corrects the parameters of the function (median size and uniformity index) with calibration factors derived from model studies. The calibration factors are functions of the uniformity index, claimed by the authors to be, with cautions, of general validity.

(iv) The mesh sizes assigned to a certain fragment may be different for sieving and for image analysis, even if the delineation and scaling are correct, due to the shape effect.

(v) A constant density is generally assumed for all the sizes so that volume distributions from image analysis are directly compared with the mass distributions obtained by sieving. The calibration factors, if obtained from mass distributions, help to solve this problem.

Despite of the foregoing weaknesses, there are examples in the literature that show how size distributions from image analysis of material in muckpiles and conveyor belts match the sieved ones quite well (Girdner et al., 1996; Kemeny et al., 1999; Segarra et al., 2005; Sanchidrián et al., 2006); for many applications, it may be sufficient that the system be consistently sensitive to changes in the distributions towards coarser or finer sizes. Latham et al. (2003) check the consistency of four major image analysis systems, Fragscan, PowerSieve, Split and WipFrag, on artificially-built rock fragment samples of Rosin-Rammler type with uniformity indexes, $n$, ranging from 0.5 to 1.75 and median size, $x_{50}$, between 15 and $52 \mathrm{~mm}$. Most methods tend to over-predict $x_{50}$ for material with small $x_{50}$ and to under-predict $x_{50}$ for material with a large $x_{50}$. For the more uniform size distributions, all systems (except Fragscan) closely predict the $n$-values, whereas for those with $n<0.9$ the $n$-values are slightly overestimated. Sanchidrián et al. (2006) show that image analysis of the run of mine rock from 35 blasts with variable overburden of fine material (natural fines) requires a variable fines adjustment factor (increasing with the amount of fines) for it to be sensitive to changes in fragmentation in a consistent manner.

Recent work (Ouchterlony, 2005a, b) on more than 300 sets of sieved data from bench blasting in quarries, reef blasting, model blasting and crushing of many different rock types, concrete and mortar has shown that the use of the RR function is misleading both in the coarse and the fine ranges, as: i) there is always a maximum fragment size ( $x_{\max }$, for which the passing is $100 \%$ ) whereas the RR function has an asymptote at $100 \%$, and ii) the fines tail does not display a linear behavior in a log-log diagram, except possibly in the ultra fine region. In order to solve this, a threeparameter size distribution function (the Swebrec ${ }^{\circledR}$ function) was developed, which can describe fragmentation across the range $1-500 \mathrm{~mm}$ quite accurately:

$$
P(x)=\frac{1}{1+\left[\ln \left(x_{\max } / x\right) / \ln \left(x_{\max } / x_{50}\right)\right]^{b}}
$$




\section{J. A. Sanchidrián et al.}

Ouchterlony (2005b) suggests that the Swebrec function, given its universal validity, could be used to extend towards the fines range the size distribution curves from image analysis - which may be fairly accurate in the coarse range - , thus widening the modest size range of this analysis.

The present work assesses the performance of image analysis on photographs of material for which there are also size distributions obtained by sieving. The ability of some functions in fitting the measured data and in extrapolating towards the fine region is also checked. It all points to the way in which an optimum analysis of fragmentation by image analysis can be done more efficiently, and the accuracy that should be expected.

\section{Description of the data}

During the "Less Fines" project (Moser, 2003), samples of fragmented rock were sieved and photographed in two quarries: El Alto (a limestone quarry in the province of Madrid, Spain) and Klinthagen (a limestone quarry on the island of Gotland, Sweden).

One of the samples (labeled A1) was obtained from muckpile material in El Alto. A Powerscreen Turbo Chieftain 1400 mobile screen was used to sieve a representative sample of a muckpile on site. The mobile screen consisted of a grizzly and two screens, with openings of $110 \mathrm{~mm}, 48$ and $20 \mathrm{~mm}$, respectively. A sample of the finer fraction was further screened in the laboratory with 13 meshes down to $0.063 \mathrm{~mm}$ (Sanchidrián et al., 2006). The muckpile sample was hauled in four trucks and a photograph was made upon dumping of each truck in the hopper of the primary crusher, where there was a permanent monitoring system with an optical resolution (the minimum size of a contour that can be delineated, a multiple of the real size of one pixel of the image) of about $50 \mathrm{~mm}$ (Tessier et al., 2002). The four photographs were merged into one size distribution in the image analysis.

Two samples, labeled A2 and A3, of the material on the conveyor belt issuing from the primary crusher in El Alto (a hammer mill with a bottom grizzly of $65 \mathrm{~mm}$ opening) were taken in July 2002 and March 2003, respectively. The sampling procedure is described by Sanchidrián et al. (2006). They were sieved from 80 to $5 \mathrm{~mm}$ (A2) and from 63 to $0.063 \mathrm{~mm}$ (A3). Previously, a photograph was taken of each of the samples on the belt. The optical resolution of these photographs was approximately $5 \mathrm{~mm}$.

Nineteen belt cuts were photographed and sampled in Klinthagen in the spring of 2003. The samples were taken $150 \mathrm{~m}$ downstream the crusher - a tooth roller crusher with a roller grizzly that scalps the incoming $<250 \mathrm{~mm}$ material (Ouchterlony, $2005 \mathrm{~b})$. At the sampling point, there was a camera with a $10 \mathrm{~mm}$ resolution (Ouchterlony, 2003b; p. 80; Ouchterlony et al., 2003). The samples are labeled K1-K19.

Figures 1 and 2 show some of the photographs. El Alto's muckpile is a combination of rock fragmented in the blast and additional fine material (about 11\%) coming from an overburden of clayey marl that is mined together with the limestone. The same fine material, together with the crushed rock, is present on the belt. The belt cut photograph A3 belongs to the blast in which the muckpile sieving was done. The 


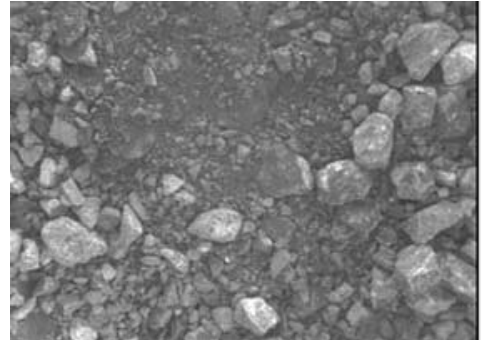

(a)

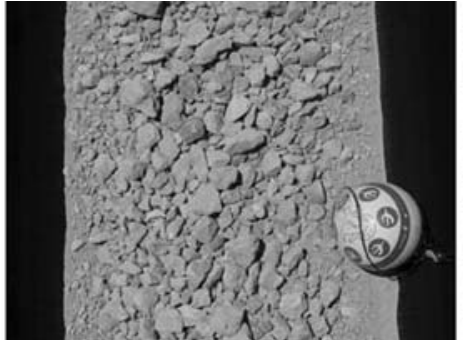

(b)

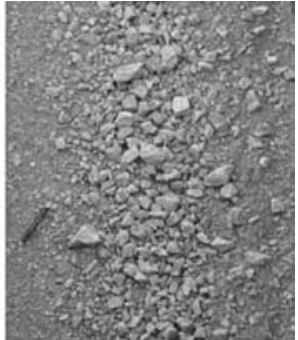

(c)

Fig. 1. Photographs in El Alto. (a) One of the four images of A1 (muckpile); (b) A2; (c) A3

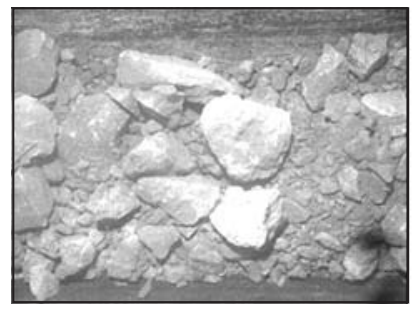

(a)

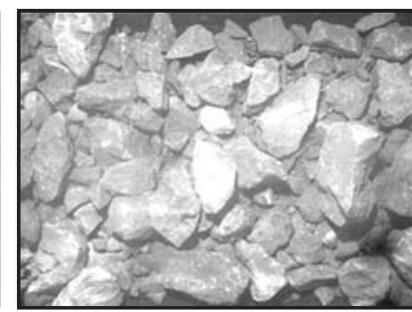

(b)

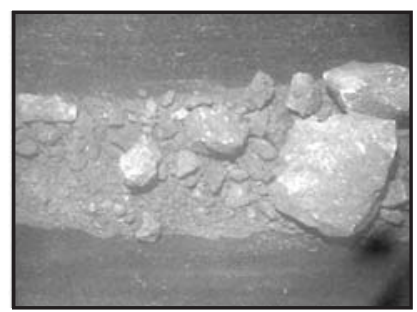

(c)

Fig. 2. Photographs in Klinthagen. (a) K7; (b) K1; (c) K16

photographs were taken from a bridge above the belt. The line of sight was carefully oriented vertically. This, plus the fact that the level of the material's surface is quite even, should result in a uniform and quite precise scaling.

Some of the Klinthagen's images, like the photograph of belt cut K7 (Fig. 2a), show fragments of crushed limestone together with the run of mine rock that has bypassed the crusher, whereas in others (see the image of sample K1 in Fig. 2b), the crushed material hides the fragments beneath them that have passed through the grizzly. Obviously, the sieving data includes material from both streams. Sample K16 (Fig. 2c) is an example of a partially empty conveyor belt with few crushed fragments. Two of them occupy about one third of the rock surface.

Each of the Klinthagen's samples was run manually in situ over a $200 \mathrm{~mm}$ square mesh-size, the retained material weighed and the passing taken to the laboratory for sieving down to $8 \mathrm{~mm}$ with seven meshes $(100,75,50,31.5,25,12.5$, and $8 \mathrm{~mm}$ ); some of them were further sieved down to $0.063 \mathrm{~mm}$. The $200 \mathrm{~mm}$ point did not fit in with a regular distribution (see Fig. 3), partially because it was not determined by standard sieving procedures (Ouchterlony et al., 2004) or because the $>200 \mathrm{~mm}$ fragments weight about $20 \mathrm{~kg}$ and there were relatively few of them (Ouchterlony, 2003b, p. 76). The size distribution curve for sizes greater than $100 \mathrm{~mm}$ hence has a larger error; a maximum size of $250 \mathrm{~mm}$ has been assumed in the plots of Fig. 3 . 


\section{J. A. Sanchidrián et al.}

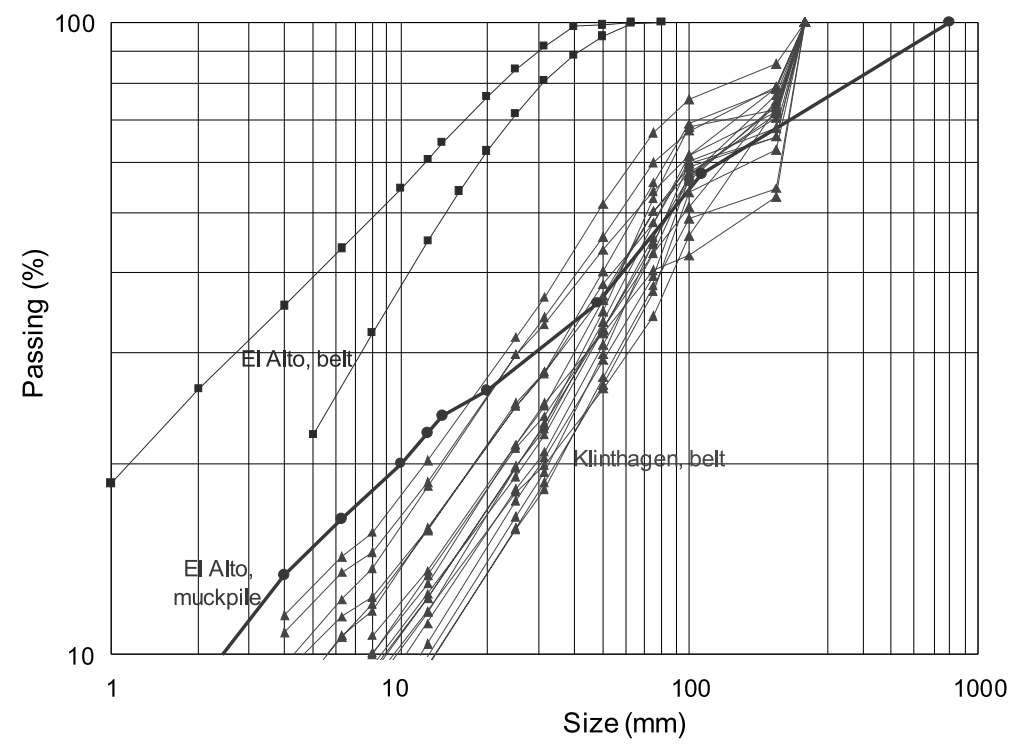

Fig. 3. Size distribution curves from sieving

\section{Image analysis and distributions fitting}

The Split ${ }^{\odot}$ Desktop image analysis software has been used in the present study. In its standard mode of operation, Split gives a size distribution based on (Kemeny et al., 1999):

- The size count of delineated particles (the output of the delineation algorithm). Surfaces delineated are converted to volumes assuming that the third dimension of each fragment is the geometric mean of the two axes of an ellipse best-fitting the particle contour and with the same area. Statistical algorithms are applied to correct the volumes for overlap and shape.

- The non-delineated material with sizes below the system resolution, i.e. "fines". A limiting size called the fines cut-off (FCO) is defined as that below which the delineation is not reliable. The FCO point is related to the size at which the size probability density function has a maximum.

- A fines correction factor (FF), which represents the percentage of the non-delineated material that is actually made of fine particles. The rest may be shadows, empty intergranular spaces, etc. This factor must be entered by the user and can be less than $100 \%$ (if not all of the non-delineated material is actually fines) or greater than $100 \%$ (if the material has actually more fines than what appears in the image, e.g. due to segregation).

- A size distribution function that extrapolates the curve below the FCO.

All the photographs pertaining the sieved distributions known were analyzed with Split in automatic mode. The major errors of the automatic delineation made by the code were then corrected manually. Details of the procedure are given by Sanchidrián 
et al. (2006). The Split data were afterwards processed in different ways (in brackets are the short name given to each analysis):

(i) Split's ordinary volume-based analysis with a fines factor equal to $100 \%$ [V1].

(ii) Split's ordinary analysis with an optimum fines correction factor [V2]. This factor was obtained as that minimizing the sum of squared relative errors (SSRE) between the code output $P_{i}$ and the sieved values $P_{i}^{S}$ :

$$
\mathrm{SSRE}=\sum_{i=1}^{N}\left[\frac{\left(P_{i}-P_{i}^{S}\right)}{P_{i}^{S}}\right]^{2}
$$

The sum extends to as many points, $N$, for which there is a sieved value, except the very fine material far below the FCO size, where errors are usually very large. Using additional points in the fines range would give too much relevance to this region, which is actually unresolved in the image analysis, and where the passing values are the results of an extrapolation. The ranges used were from the maximum size to: $4 \mathrm{~mm}$ in $\mathrm{A} 1,5 \mathrm{~mm}$ in $\mathrm{A} 2,4 \mathrm{~mm}$ in $\mathrm{A} 3$ and $8 \mathrm{~mm}$ in $\mathrm{K} 1$ through $\mathrm{K} 19$. In the latter, the sieved values at $200 \mathrm{~mm}$ were not used in the determination of the optimum fines factors.

(iii) Split's ordinary analysis with the optimum fines factor determined so as to minimize the SSRE for sizes greater than the FCO (or the closer point below that) [V3].

Some common functions used to describe fragment size distributions have been fit to the Split's results V2:

(iv) Weibull-Rosin-Rammler [V2-RR].

(v) Swebrec [V2-SW].

(vi) Lognormal [V2-LN].

The range used for the fitting is from the maximum size to the FCO, or, when it does not coincide with a mesh size, the mesh size closer to this (either above or below). The passing values below the FCO are themselves the result of a function fitting, done by the image analysis code, so they have not been used. The least squared error criterion has been used in the non-linear regressions. Weighing functions such as $1 / x$ or $1 / x^{1 / 2}$ are sometimes used in this type of fitting (Ouchterlony, 2003b; p. 12); they have not been used in the present case as the range of $x$ is limited to less than one order of magnitude, given that only points near the FCO and higher have been used for the fittings.

The functions obtained are applied to the size range $\left[x_{10}, x_{90}\right]$. Such procedure tests, besides the goodness of the fitting in the region used for it, the ability of these functions to extrapolate the size distributions towards the fines.

Split, like other digital image software, e.g. Fragscan and Wipfrag, provides size distribution curves in volume. Volume estimation from the visible dimensions of the fragments leads to a significant percentage of material in the upper size class, resulting in a locally high slope of the cumulative distribution curve. This can be seen in Fig. 4, where the cumulative size distribution curves for El Alto's A1-A3 and Klinthagen's $\mathrm{K} 2-\mathrm{K} 4$ samples are plotted as a matter of example. The curves shown as dotted lines are obtained directly from the volume of the fragments calculated based on the delineated particles (they are not a final output of the code), assuming a fraction of fines equal to the fraction of non-delineated surface, i.e. a fines correction factor equal to $100 \%$. The 


\section{J. A. Sanchidrián et al.}

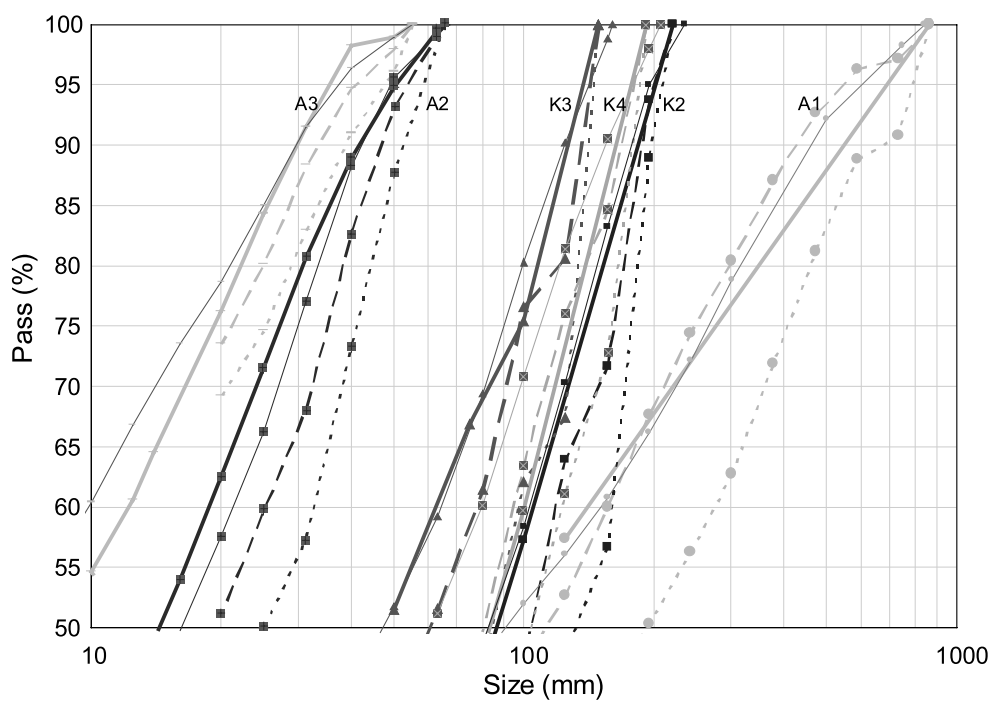

Fig. 4. Comparison of size distribution curves from image analysis, based on volume (dotted lines) and on areas (dashed lines) of fragments. Thick solid lines are size distributions from sieving. Thin solid lines are the final Split curves without fines correction (fines factor 100\%)

sieved curves (thick solid lines) are drawn for comparison; the maximum size of the sieved curves has been made equal to the maximum size measured in the image analysis.

The origin of the large amount of material in the larger size class is sketched in Fig. 5. Larger fragments in the surface also have greater depths. The effective sample volume is then deformed, being thicker in the zone where there are large fragments in the surface and thinner where there are small fragments, thus biasing the volume
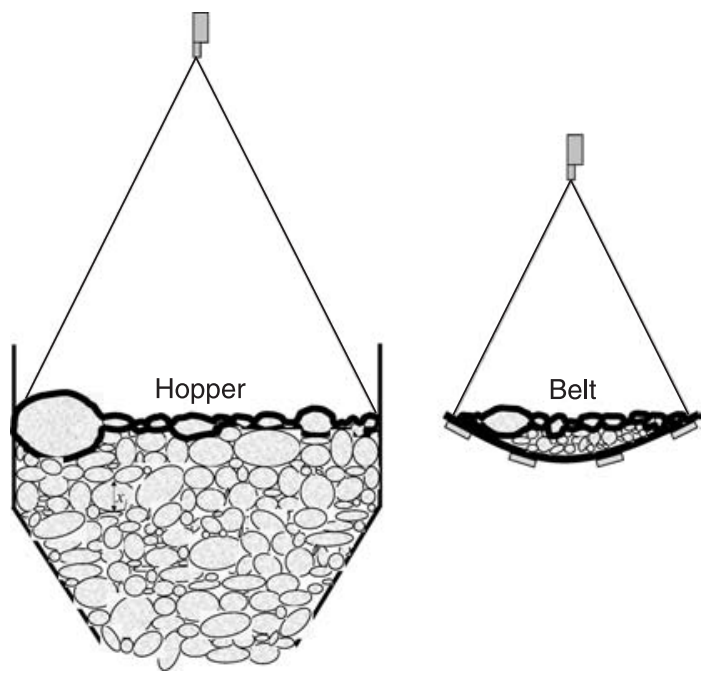

Fig. 5. Section of fragments in a bin and in a conveyor belt. Thick lines are the sampling volumes in the image analysis 
count. In the sample depicted in Fig. 5, the large fragment on the left, which occupies about $20 \%$ of the image surface, makes up about $50 \%$ of the volume of the delineated particles. This would not be so if a volume of depth equal to the depth of the large fragment were considered.

This phenomenon is of course corrected by the codes; the histogram of volumes is made up from hypotheses about the particle shapes, overlap between fragments and estimation of the non-photographed particles at depth (Cunningham, 1996; Split Engineering, 2001; Ouchterlony, 2003a) that modify the original frequencies in volume of the delineated particles. In some cases, the frequency of the particles in the upper class is reduced acting upon the original fragment sizes (Girdner et al., 1996) or the number of particles (Maerz, 1996). Some of the particles in this size class are redistributed towards classes of smaller sizes or towards a new class of greater size. The final output of the analysis with Split using a fines correction factor of $100 \%$ is shown in Fig. 4 as thin solid lines.

The surface-based distributions in Fig. 4 (dashed lines) are calculated from the original delineated particle count, using as fines all the non-delineated area (i.e. as if a fines factor of $100 \%$ were used, in a similar way as in the volume-based distributions). They show a smoother drop in the largest class and in many cases, they appear to follow quite acceptably the actual (sieved) size distribution. This suggests the approach of using surface-based distributions and obtaining a fines correction factor directly from them. Functions are then fitted to the resulting distribution. The following analyses have been done with this approach, following the (i) to (vi) above:

(vii) Surface-based distribution with a fines factor equal to $100 \%$ [S1].

(viii) Surface-based distribution with an optimum fines factor [S2]. The optimum fines factor has been obtained in a similar way as for analysis V3, i.e. the data below the FCO have not been used (or only one point, if it is the closer one to the FCO) for the adjustment of the fines factor.

In both S1 and S2 calculations, the curves obtained down to the FCO (or the mesh size closer to it) are logarithmically extrapolated downwards using the two lower points (equivalent to a Gaudin-Schuhmann extrapolation).

(ix) Weibull-Rosin-Rammler fitting to the S2 distribution [S2-RR].

(x) Swebrec fitting to the S2 distribution [S2-SW].

(xi) Lognormal fitting to the S2 distribution [S2-LN].

As with the volume distributions, all regressions are carried out from the maximum size to the FCO or to the closer mesh size.

Table 1 gives some parameters of the size distributions and of the image processing. The sizes $x_{90}, x_{50}$, and $x_{10}$ are sieved values and $x_{\max }$ is the value given by Split. Figure 6 shows an example of the eleven distributions calculated for sample K7 (corresponding to the photograph in Fig. 2a).

For each analysis (i) to (xi), the mesh sizes obtained, $x_{P_{i}}\left(P_{i}=10,20, \ldots, 90\right)$, have been compared with the corresponding sieved values $x_{P_{i}}^{S}$ and the relative errors calculated:

$$
e_{R i}=\frac{x_{P_{i}}-x_{P_{i}}^{S}}{x_{P_{i}}^{S}}
$$




\section{J. A. Sanchidrián et al.}

Table 1. Properties of the size distributions

\begin{tabular}{|c|c|c|c|c|c|c|c|c|c|c|}
\hline Sample & $\begin{array}{l}x_{\max } \\
(\mathrm{mm})\end{array}$ & $\begin{array}{l}x_{90} \\
(\mathrm{~mm})\end{array}$ & $\begin{array}{l}x_{50} \\
(\mathrm{~mm})\end{array}$ & $\begin{array}{l}x_{10} \\
(\mathrm{~mm})\end{array}$ & $s_{50}$ & $\begin{array}{l}\mathrm{FF}, \text { all } \\
\text { range }(\%)\end{array}$ & $\begin{array}{l}\text { FF, fit to } \\
\text { FCO }(\%)\end{array}$ & $\begin{array}{l}\text { FF, surface } \\
(\%)\end{array}$ & $\begin{array}{l}\text { FCO } \\
(\mathrm{mm})\end{array}$ & $\begin{array}{l}\text { Passing at } \\
\text { FCO }(\%)\end{array}$ \\
\hline K1 & 221.4 & 186.3 & 64.9 & 4.3 & 0.515 & 80 & 70 & 100 & 59 & 47.5 \\
\hline $\mathrm{K} 2$ & 234.8 & 199.8 & 87.2 & 10.6 & 0.899 & 100 & 80 & 168 & 82 & 47.2 \\
\hline $\mathrm{K} 3$ & 160.1 & 134.3 & 48.1 & 2.9 & 0.695 & 90 & 90 & 161 & 52 & 52.7 \\
\hline K4 & 207.5 & 178.8 & 84.1 & 9.0 & 0.947 & 50 & 10 & 63 & 70 & 42.5 \\
\hline K5 & 193.4 & 162.4 & 57.2 & 3.4 & 0.662 & 80 & 70 & 134 & 65 & 54.5 \\
\hline K6 & 221.4 & 190.9 & 84.4 & 8.6 & 0.773 & 140 & 50 & 169 & 74 & 45.0 \\
\hline K7 & 205.3 & 175.5 & 78.3 & 8.8 & 0.870 & 150 & 60 & 191 & 64 & 41.9 \\
\hline K8 & 253.7 & 209.1 & 78.6 & 5.5 & 0.675 & 50 & 20 & 65 & 65 & 44.8 \\
\hline K9 & 227.6 & 196.0 & 86.2 & 12.7 & 0.806 & 100 & 60 & 169 & 68 & 40.6 \\
\hline K10 & 296.5 & 246.6 & 94.5 & 13.3 & 0.989 & 120 & 60 & 126 & 68 & 34.9 \\
\hline K11 & 214.4 & 184.0 & 74.5 & 4.7 & 0.672 & 60 & 50 & 81 & 67 & 46.1 \\
\hline K12 & 224.3 & 178.0 & 65.5 & 5.6 & 0.792 & 60 & 50 & 82 & 54 & 42.8 \\
\hline K13 & 184.7 & 164.2 & 74.5 & 7.9 & 0.669 & 90 & 40 & 139 & 66 & 45.4 \\
\hline K14 & 245.1 & 214.9 & 103.0 & 13.3 & 0.823 & 30 & 30 & 46 & 63 & 33.1 \\
\hline K15 & 173.7 & 149.1 & 71.4 & 9.8 & 0.975 & 40 & 30 & 35 & 35 & 25.8 \\
\hline K16 & 309.2 & 268.9 & 123.4 & 7.0 & 0.590 & 20 & 20 & 18 & 44 & 30.0 \\
\hline K17 & 228.8 & 200.9 & 96.6 & 8.0 & 0.699 & 90 & 100 & 82 & 50 & 32.7 \\
\hline K18 & 205.5 & 180.0 & 90.5 & 11.7 & 1.129 & 80 & 30 & 85 & 71 & 38.2 \\
\hline K19 & 243.2 & 215.7 & 110.3 & 9.5 & 0.915 & 100 & 40 & 85 & 83 & 38.4 \\
\hline A1 & 842.0 & 586.4 & 94.3 & 2.4 & 0.453 & 110 & 110 & 100 & 83 & 47.0 \\
\hline A2 & 65.3 & 41.7 & 14.4 & 1.8 & 0.716 & 110 & 140 & 200 & 19 & 60.4 \\
\hline A3 & 54.9 & 30.1 & 8.3 & 0.4 & 0.469 & 80 & 80 & 102 & 15 & 66.4 \\
\hline
\end{tabular}

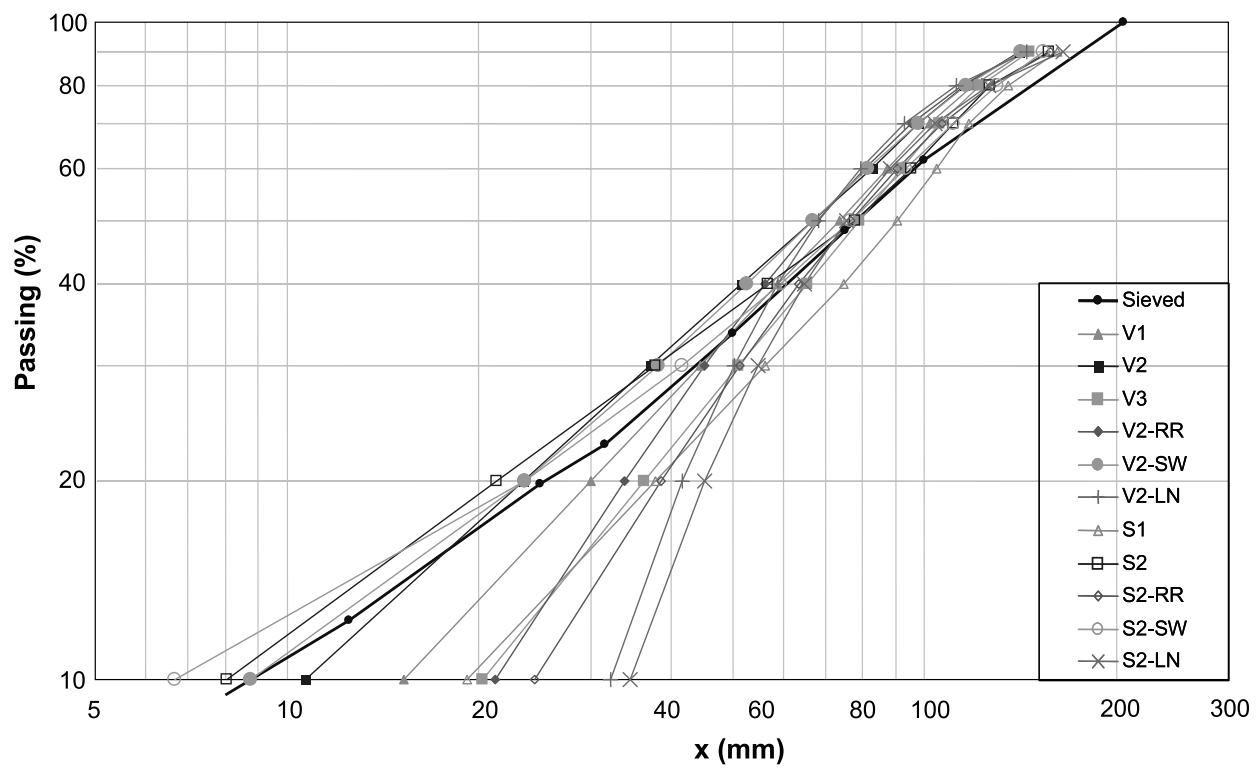

Fig. 6. Example of size distribution calculations (photograph sample K7)

The sieved sizes at a given percentage passing are obtained by logarithmic interpolation between the two sizes at the closest passing values below and above. Where the percentage passing at the finer size sieved is greater than $10 \%$, the size $x_{10}$ is 
obtained by logarithmic extrapolation from the lower two points available. This happens in 3 of the 22 size distributions studied. Only in one of these (A2) the lower percentage passing of the sieving is greater than $20 \%$.

Although the determination of the fines correction factors and the fitting of distribution functions have been carried out in a traditional way so that the errors in the percentage passing (the ordinate in the usual representation of size distribution curves) are minimized, the accuracy assessment based on the errors in size has been chosen because size estimation is the typical result that an image analysis user will look at (e.g. what is $x_{50}$ or $x_{80}$, etc.) as measures of the distribution's position, skewness and curtosis. Sizes are involved in fragmentation models (Cunningham, 1983, 1987; Ouchterlony et al., 1990; Kou and Rustan, 1993; Chung and Katsabanis, 2000) and in the estimations of the work index for calculations of crushers energy and throughput (Bond, 1952), thus being the preferred way of describing fragment distributions. The fines factor determination and the function fitting could have been carried out with a target of minimum error in size; this was dismissed because fitting some of the functions involved - RR and lognormal, with a vertical asymptote in $(P, x)$ axes can only be done by rejecting the maximum size, or assuming a percentage passing close to 100 for it. In this case, the result of the fitting depends largely on what percentage passing value is assigned to the maximum size. Moreover, the errors in the maximum size are expected to be large because the population is scarce in that range; few individuals result in poor statistics.

The error in the determination of the slope, $s_{50}$, of the cumulative distribution at $x_{50}$ has also been assessed. The logarithmic slope is used:

$$
s_{50}=\left(\frac{d \log P}{d \log x}\right)_{x_{50}}=\left(\frac{d \ln P}{d \ln x}\right)_{x_{50}}=\left(\frac{d P}{d x} \frac{x}{P}\right)_{x_{50}}=2 x_{50}\left(\frac{d P}{d x}\right)_{x_{50}}
$$

$s_{50}$ is a measure of the dispersion of the size distribution. For the functions used in this work, the dispersion parameters are:

- The Rosin-Rammler's uniformity index, $n: n=s_{50} / \ln 2$.

- The Swebrec's undulation parameter, $b: b=2 s_{50} \ln \left(x_{\max } / x_{50}\right)$.

- The lognormal's standard deviation, $s: s=\left(1 / s_{50}\right) \sqrt{2 / \pi}$.

\section{Results and discussion}

\subsection{Size determination}

The relative errors in size, $e_{R}$, are plotted as a function of the percentage passing, for each calculation method, in Fig. 7. Different markers are used for the different groups of samples: El Alto's muckpile (A1) and belt (A2-A3), and Klinthagen's belt (K1-K19). The scale of the vertical axis varies from one graph to another, depending on the value of the maximum errors for each calculation method. Lines show the $95 \%$ confidence bands. Though the relative error is a simple and meaningful measure of the deviation of the calculated values from the actual ones, it is flawed in the sense that it gives less weight to underpredictions than to overpredictions, resulting in biased statistics; if confidence bands are determined directly on the relative errors they fall in 


\section{J. A. Sanchidrián et al.}
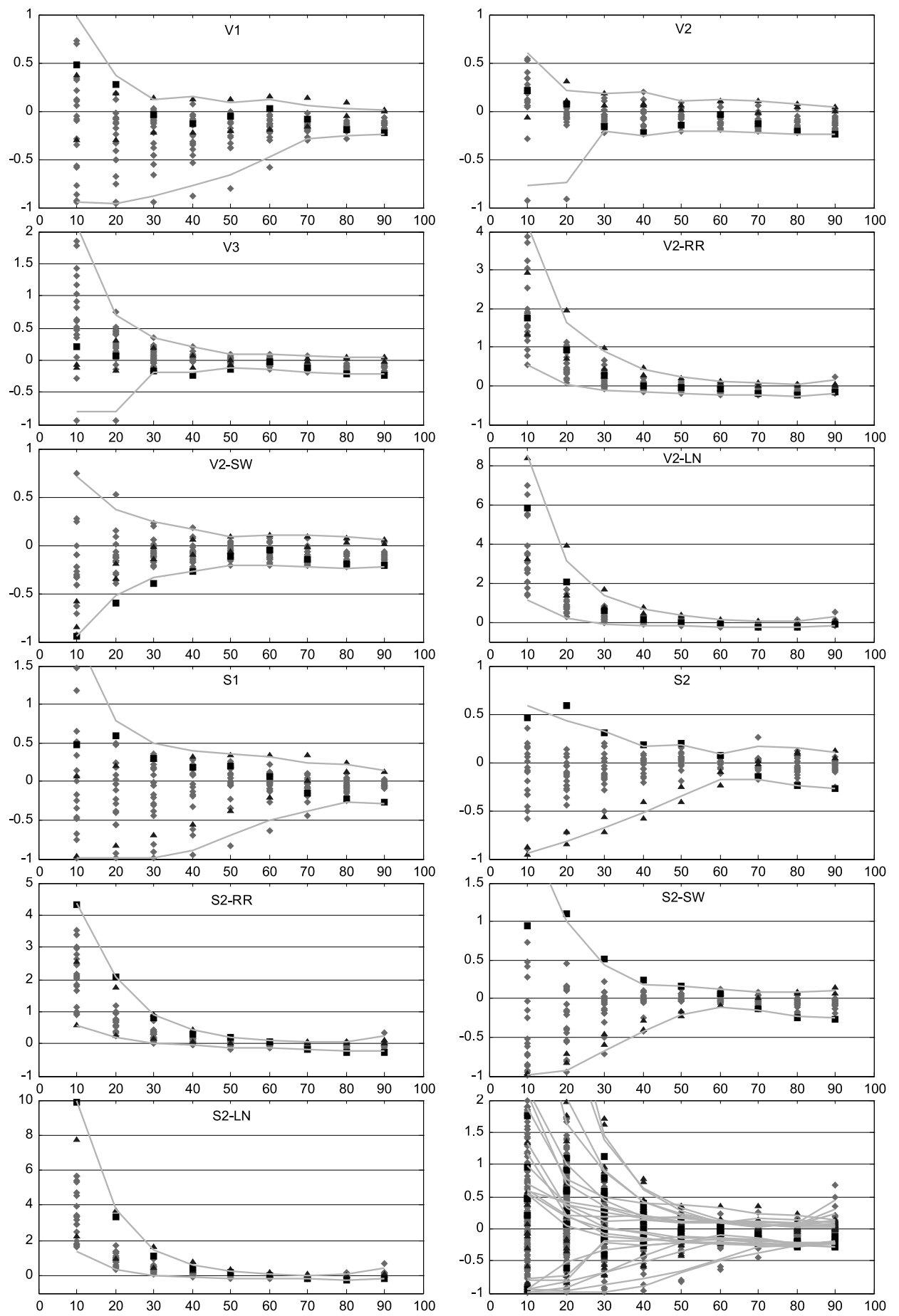

Fig. 7. Relative errors in the determination of sizes as a function of the percentage passing. Each graph corresponds to a calculation method. Different markers are used for each group of samples; diamonds: K1-K19, squares: A1, triangles: A2-A3. Lines show the 2.5 and 97.5 percentiles. The lower right plot shows all the errors and bands 
some cases below -1 , which lacks sense. To overcome this, logarithmic errors are calculated:

$$
e_{L i}=\ln \left(\frac{x_{P_{i}}}{x_{P_{i}}^{S}}\right)=\ln \left(e_{R i}+1\right)
$$

which are fully symmetric with respect to zero (e.g. a value calculated double than the sieved one is rated with a relative error $e_{R}=1$ and a value half is rated $e_{R}=-0.5$, while the $\operatorname{logarithmic}$ errors are $\ln 2$ and $-\ln 2$ ). The confidence bands are obtained as the quantiles, $q_{\alpha}$ and $q_{1-\alpha}$, of the logarithmic errors at each passing, calculated by:

$$
\left(q_{L}\right)_{1-\alpha}^{\alpha}=\left(q_{L}\right)_{1 / n}^{1 / n} \underset{1-n}{ } \mp\left[N^{-1}(1 / n)-N^{-1}(\alpha)\right] \sigma_{L}^{*}
$$

with $\alpha=0.025$ for a $95 \%$ band; $n$ is the number of samples for each passing value and each method ( $n=22$ in the present case), so that the extreme quantiles that can be calculated based on the actual data are $q_{1 / n}$ and $q_{1-1 / n} . N^{-1}$ is the inverse of the cumulative standard normal distribution and $\sigma^{*}$ is a robust estimate of the standard deviation of the logarithmic errors at each passing, obtained from the median absolute deviation about the median (MAD), $\sigma^{*}=1.4826 \cdot$ MAD.

The quantiles for the relative errors are, finally:

$$
q_{1-\alpha}^{\alpha}=\exp \left(q_{L}\right)_{1-\alpha}^{\alpha}-1
$$

Errors are not random, nor are zero-centered, but follow some trends in size and sign with the percentage passing. In general, the errors are limited at large percentages passing (i.e. large sizes), positive or negative depending both on the group of samples and the calculation method. For instance, the Klinthagen samples' errors are generally negative in the coarse range, probably due to the fact that in this range the reference values (sieved) are a linear interpolation in log-log space between the value at $100 \mathrm{~mm}$ and the maximum size (see Fig. 6). Errors of the A2-A3 samples in most of the volume calculations tend to be in the upper range, in agreement with the results by Latham et al. (2003) on the trend of overprediction of $x_{50}$ by image analysis methods when it is small, which is the case for these two samples compared with the rest.

In the central range of sizes, errors are still generally small, oscillating in many cases above or below zero. As the size gets smaller, the errors increase, in some cases dramatically in the finer range. Errors in the fines are generally positive, which means that the sizes calculated are usually larger than the actual (sieved) ones or, in other words, that the calculations generally underpredict the amount of fines. The reason for this is that the calculated distributions usually have a higher slope in the fines range than the sieved ones. There are some exceptions to this in the different groups of samples: 1) the Swebrec fits give negative errors for the small sizes, due to its undulation characteristic that makes the curve dip less abruptly towards the fines, and 2) the surface calculation S2, where the extrapolation, conducted from the FCO, has a typical low slope at large sizes (see for instance Fig. 6); this is particularly relevant in the $\mathrm{K} 2-\mathrm{K} 3$ samples, where the FCO is large.

Table 2 shows the correlation matrix of the relative errors of each calculation method with some characteristic parameters: the percentage passing, $P$, the ratio of $P$ to the passing at the FCO size $[P / P(\mathrm{FCO})]$ and its equivalent in size: the ratio of the 


\section{J. A. Sanchidrián et al.}

Table 2. Correlation matrix of the relative errors in size

\begin{tabular}{|c|c|c|c|c|c|c|c|c|c|c|c|}
\hline & V1 & $\mathrm{V} 2$ & V3 & V2-RR & V2-SW & V2-LN & $\mathrm{S} 1$ & $\mathrm{~S} 2$ & S2-RR & S2-SW & S2-LN \\
\hline $\begin{array}{l}\text { Percentage } \\
\text { passing }\end{array}$ & -0.005 & -0.453 & -0.651 & $-\mathbf{0 . 8 0 2}$ & 0.120 & -0.787 & 0.001 & 0.161 & $-\mathbf{0 . 8 3 0}$ & 0.163 & -0.780 \\
\hline$P / P(\mathrm{FCO})$ & -0.145 & -0.497 & -0.633 & -0.839 & 0.106 & -0.838 & -0.154 & 0.189 & -0.869 & 0.203 & $-\mathbf{0 . 8 3 3}$ \\
\hline$x / \mathrm{FCO}$ & -0.124 & -0.482 & -0.628 & -0.836 & 0.118 & -0.834 & -0.144 & 0.170 & -0.882 & 0.187 & -0.845 \\
\hline FF-vol & 0.653 & -0.234 & -0.121 & -0.119 & -0.200 & -0.073 & 0.604 & -0.154 & -0.047 & -0.123 & -0.023 \\
\hline FF-vol-FCO & 0.576 & 0.147 & -0.172 & 0.153 & 0.046 & 0.155 & 0.525 & -0.094 & 0.082 & -0.164 & 0.100 \\
\hline FF-surf & 0.685 & -0.025 & -0.024 & 0.005 & -0.073 & 0.031 & 0.719 & -0.225 & 0.012 & -0.259 & 0.042 \\
\hline
\end{tabular}

size to the FCO $(x / \mathrm{FCO})$; the fines correction factors in both the Split's ordinary, volume calculations ("FF-vol", with the fines factor fitting all the size range available, and "FF-vol-FCO", fitting only sizes greater than the FCO), and in the surface calculation ("FF-surf"). Given the large scatter of the error data, the Spearman's correlation coefficients have been used, as they are less influenced by outliers and non-normality than the usual Pearson's. Numbers in bold and script in Table 2 mean that the correlation is statistically significant at $99 \%$ and $95 \%$ confidence levels, respectively. As expected from Fig. 7, the percentage passing has significant correlation with the errors for most of the calculation methods. Even when that correlation does not formally exist, as is the case for the non calibrated methods (V1 and S1), or is very week (for S2 and the Swebrec fits to volume and surface distributions, V2-SW and S2-SW), this is due to the compensation of positive and negative errors, whereas the absolute value of the error has an obvious dependence on the size or the percentage

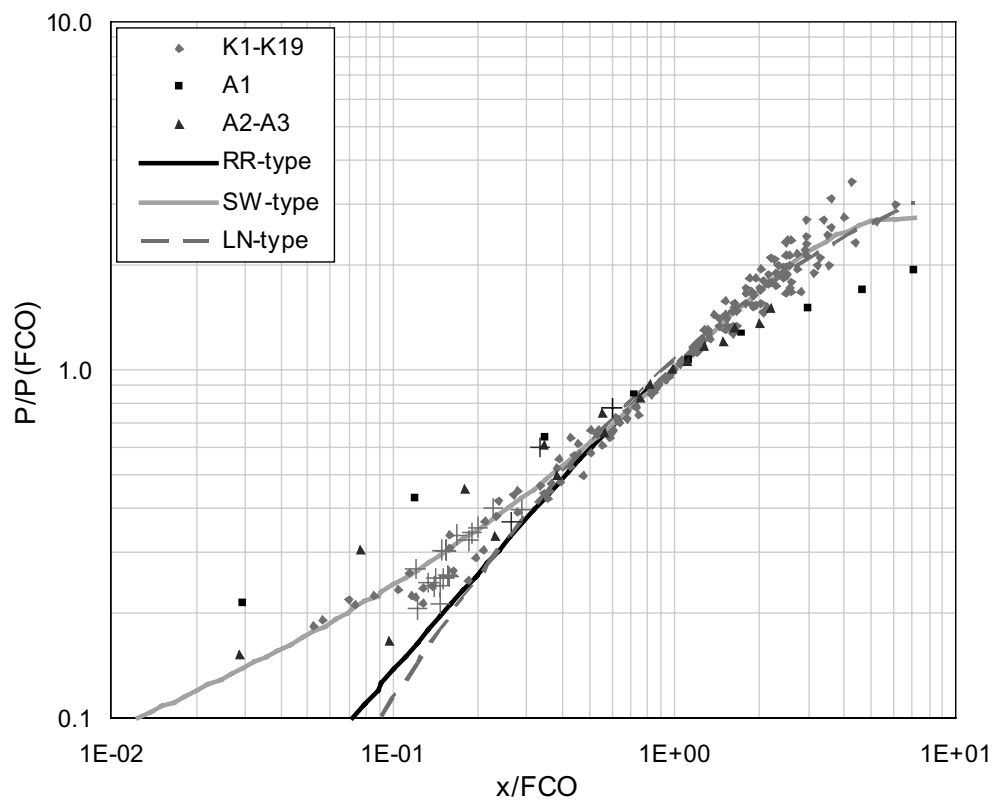

Fig. 8. Size distribution normalized with the fines cut-off size and passing. Crosses show the optical resolution points 
passing, increasing as these get smaller. The correlation improves in most of the cases, both in the value of the coefficient and in the signification, when the ratio of the percentage passing to the percentage passing at the FCO, or the ratio of size to the FCO, are used. The correlations are very similar for both ratios; actually, both have a mutual Spearman correlation coefficient of 0.98. Figure 8 gives a plot of one ratio versus the other for the $(x, P)$ sieved values. This plot represents a normalized size distribution for all samples studied and can be fitted by functions of the type of the three used for fitting the cumulative size distributions (multiplied by prefactors other than 100); the determination coefficients are 0.92 for RR, 0.93 for $\mathrm{SW}$, and 0.91 for LN. They are plotted in Fig. 8. The points corresponding to the optical resolution [Resolution/FCO, $P$ (Resolution) $/ P$ (FCO)] are also plotted.

The fines factors have strong relations with the errors in the non-calibrated methods. This is explained by the fact that sizes at a given percentage passing increase as the fines factor decreases (i.e. fewer fines are present); the distribution with a fines factor of $100 \%$ (non-calibrated) will give greater sizes than the calibrated calculation if the optimum fines factor is greater than $100 \%$, so that the relative error will tend to be positive, and it will likely be negative for an optimum factor less than $100 \%$. Some weak correlations also appear in other methods, especially with the particular fines factor used in them.

The position of the percentage passing with respect to the percentage passing at the FCO, or whether a given size is above or below the FCO, clearly plays a major part in the error at that percentage passing or size. Figure 9 shows the error plots using the ratio of the passing to the passing at the FCO as abscissa; similar plots are obtained if the ratio of size to the FCO is used. Though the dispersion is still high, the grouping of the points is much tighter when the ratio is used: see for example how the square and triangular points, with large passing values at the FCO, are shifted leftwards when the passing ratio is used; compare the plots of S2 and S2-SW errors in Figs. 7 and 9.

Confidence bands have been calculated for the errors. They are obtained by forming groups of points and determining the extreme quantiles in a similar way as described by Eqs. ( 8 and 9), with $n$ the number of data in the group. Some overlapping was allowed between consecutive groups. The quantile values are then smoothed with a suitable function; this has been found to be:

$$
\left(e_{L}\right)_{q}=\left[a \exp \left(b r_{P}^{c}\right)+d\right] r_{P}^{0.5}
$$

where $r_{P}=P / P$ (FCO) is the passing ratio. Care has been exercised so that about $5 \%$ of the points (i.e. about 10) are left outside the bands. For this, trials with different number of points in the groups and different overlapping were done in each of the error distributions. The bands are finally transformed back into relative errors:

$$
\left(e_{R}\right)_{q}=\exp \left[\left(e_{L}\right)_{q}\right]-1
$$

These bands are plotted in Fig. 9. The lower right graph gives a plot of all the errors and bands together. The higher absolute values of both bands are plotted, for each calculation method, in Fig. 10.

In general, the maximum errors expected are limited at passing ratios grater than about 1, increasing below that value. Among the "direct" calculation methods (those that do not involve a function fitting, other than the fines extrapolation: V1, V2, V3, S1 


\section{J. A. Sanchidrián et al.}
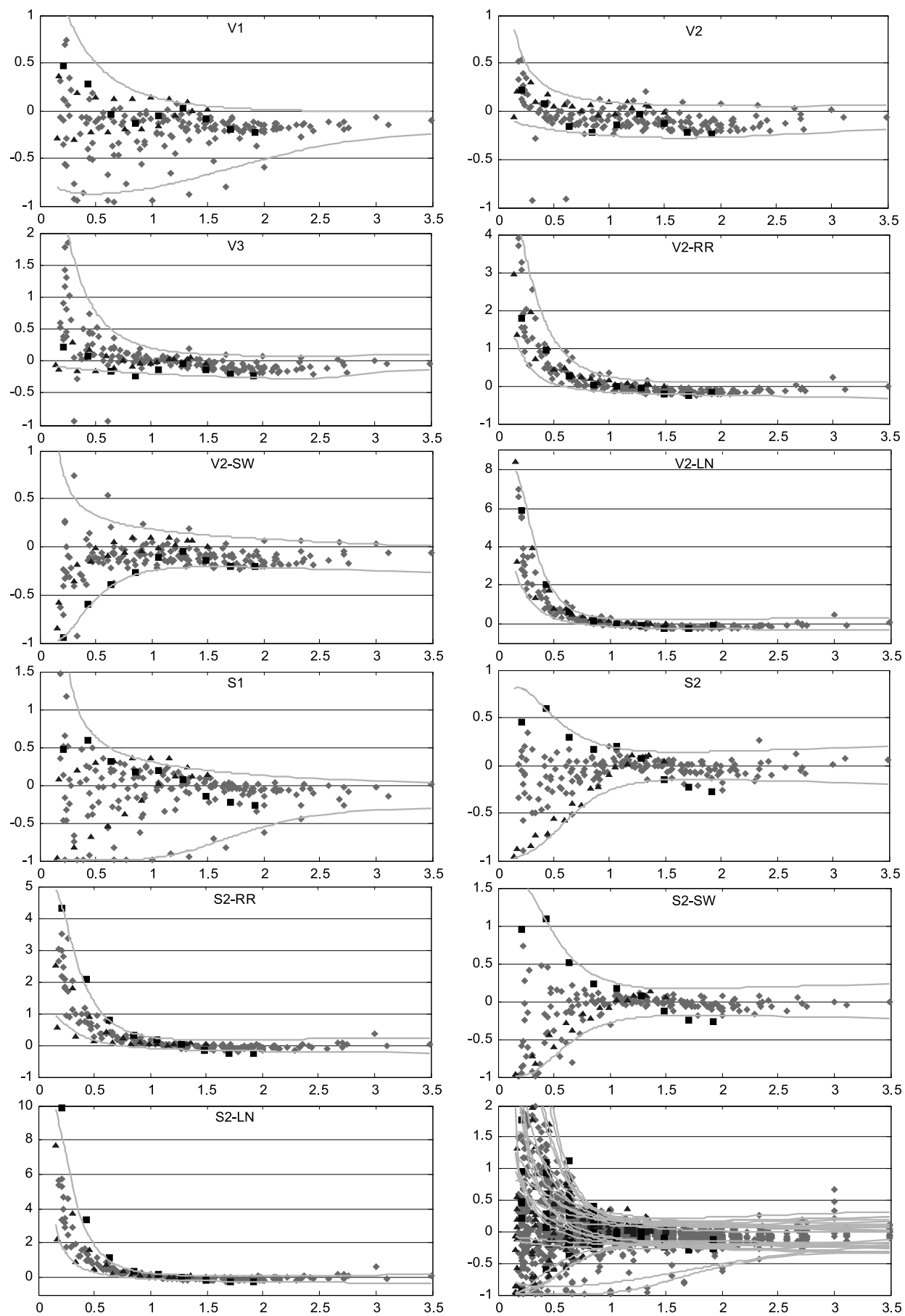

Fig. 9. Relative errors in the determination of sizes as a function of the passing ratio. Each graph corresponds to a calculation method. Different markers are used for each group of samples; diamonds: K1-K19; squares: A1; triangles: A2-A3. Lines show the $95 \%$ confidence bands. The lower right plot shows all the errors and bands 


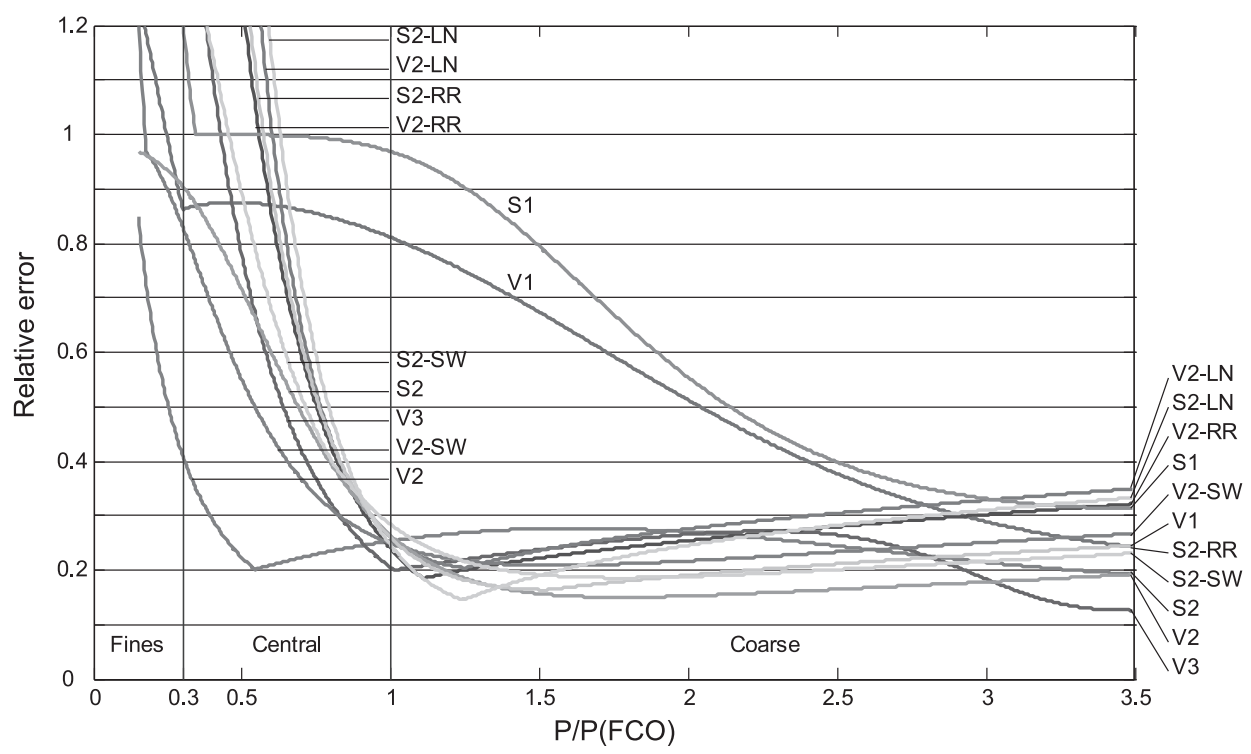

Fig. 10. Maximum absolute value of the relative errors in size expected at a $95 \%$ confidence level

and S2), the Split's ordinary output, V2, performs well in all the range analyzed, with maximum errors expected of less than $30 \%$ in most of the sizes, except in the very fine tail. This good behavior stems from the fact that the fines correction factor was determined in this calculation as that minimizing the relative error in all the range (down to percentages passing close to or, in some cases, below 10\%). Consequently, the relative error is not much dependent on the range of size or percentage passing except in the lower size limit. V3, where the fines have not been made to match the sieved values, but where only the data above the FCO have been used, has a greater uncertainty below that size. The calibrated surface calculation, S2, which is comparable to V3 in the sense that both use a fines correction factor determined from the sieved values above the FCO only (i.e. the fragments really measured), seems to perform similar to the volume-based V3, with a narrower prediction band in most of the size range; at small sizes the trend is toward negative errors for S2 and positive for V3 but the maximum errors are similar in absolute value. This means that the fines correction can somehow lump the surface-to-volume transformation. The errors of the non-calibrated calculations (V1 and S1) can be already $50 \%$ at passing ratios of 2 , increasing downwards. The accuracy of these methods depends on how far the actual optimum fines correction factor is from the $100 \%$ value used in them. The average value of the factors was $83 \%$ in the volume calculations and $109 \%$ in the surface ones, this being the main reason why, on average, the errors are limited. Obviously, this does not hold case per case and, as the variation of the fines factors (see Table 1) is quite ample in the samples studied, so the maximum error expected is.

Concerning the functions fitted, SW and RR give maximum errors of about $30 \%$ at sizes greater than the FCO; below that, RR performs poorly, with errors in excess of $100 \%$ at $r_{P}=0.5$ (sizes $0.3-0.5$ times the FCO according to Fig. 8), and higher in the finer material; V2-SW keeps the error within $50 \%$ at $r_{P}=0.5$ and not more than $100 \%$ 


\section{J. A. Sanchidrián et al.}

in the very fines; in both functions the surface calculation is worse than the volume one in the fines. The lognormal function fits are very unreliable below the FCO, with the largest errors of all the calculations; at sizes greater than the FCO they are comparable to the rest, with errors generally within $30 \%$.

Using the FCO and the optical resolution, the following passing and corresponding size ranges can be defined:

$-P / P(\mathrm{FCO})<0.3$, or $x / \mathrm{FCO}<0.2$;

$-0.3<P / P(\mathrm{FCO})<1$, or $0.2<x / \mathrm{FCO}<1$;

$-P / P(\mathrm{FCO})>1$, or $x / \mathrm{FCO}>1$.

The value $r_{P}=0.3$ is arbitrarily chosen as the median of the passing ratio at the optical resolution in the samples studied, for which the size ratio $x / F C O$ is approximately 0.2 (see Fig. 8). The three ranges correspond, respectively, to optical fines, where a qualified guessing is required and errors are potentially large, a central region where size distributions require correction for errors in the fines detection and delineation, and a coarse region where errors are relatively small. For the data used in this work, the optical size ranges correspond to: coarse, all of the 90, 80, and 70\% passing, most of the $60 \%$ and $50 \%$, and few of the $40 \%$ and $30 \%$; central, few of the $60 \%$ and $50 \%$, most of the $40 \%$ and the $30 \%$, all of the $20 \%$ and few of the $10 \%$; fines, most of the $10 \%$. The maximum errors that can be incurred with the best methods in each range are the following:

- Optical coarse range: all calibrated calculations, 30\%.

- Optical central range: V2, 40\%; V2-SW, 85\%; S2, 90\%; V1, 90\%.

- Optical fine range: V2, 85\%; S2, $100 \%$.

\subsection{Slope determination}

The relative errors in the determination of $s_{50}$ for the various calculation methods are plotted in Fig. 11. The triangles show the 0.025 and 0.975 quantiles determined as from Eqs. (7-9). The maximum absolute values of those are marked with diamonds. The maximum errors to be expected in the determination of $s_{50}$ are of the order of the errors in the determination of the sizes at around the mid central range. Considering that the median size is in the majority of cases (18 of 22) in the coarse range, this means that the shape of the curve is already in that point distorted from the actual one, this being the reason for the large errors downwards. This is confirmed by the fact that such errors tend to be of the same sign as those in the $s_{50}$.

A correlation analysis has been done of the errors in $s_{50}$ with some parameters of the size distribution as shown in Table 3. Spearman's correlation coefficients have also been used here. The correlations significant to $99 \%$ and $95 \%$ confidence levels appear in bold and script characters, respectively. There are no clear dependencies that could be explained in physical terms except for the errors of the non-calibrated methods, V1 and S1, with the fines correction factors. This reflects the fact that the higher the fines factor used in the calculation the smaller the slope must be in order to accommodate a larger amount of fines. If the optimum fines factor is greater than $100 \%$, a calculation with $\mathrm{FF}=100 \%$ gives a higher slope and then a positive relative error. The opposite is true for an optimum fines factor less than $100 \%$. 


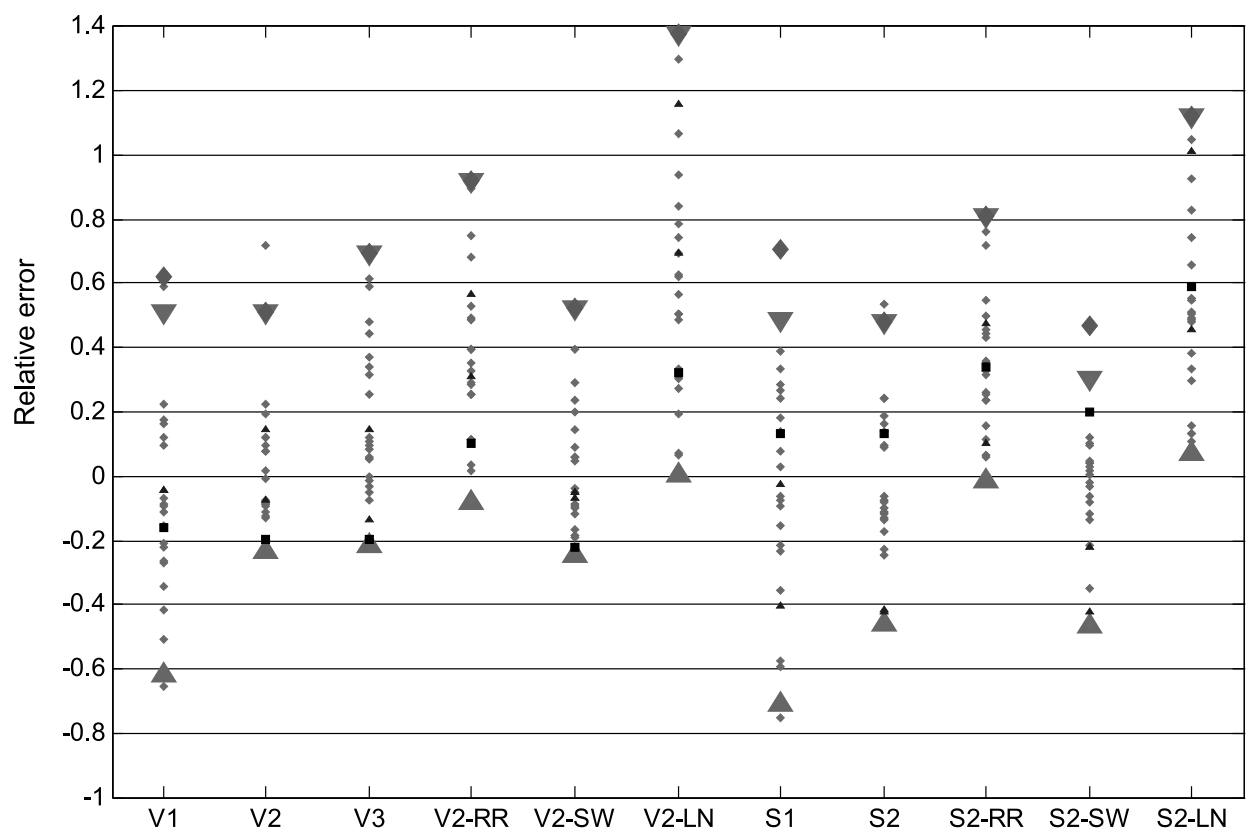

Fig. 11. Relative errors in the determination of s50. Triangles show the 2.5 and 97.5 percentiles. Diamonds show the maximum absolute value of those

Table 3. Correlation matrix of the relative errors in slope at $50 \%$ passing

\begin{tabular}{lrllllllllll}
\hline & V1 & V2 & V3 & V2-RR & V2-SW & V2-LN & S1 & S2 & S2-RR & S2-SW & S2-LN \\
\hline$s_{50}$ & -0.149 & -0.505 & -0.041 & $-\mathbf{0 . 6 2 6}$ & -0.339 & $-\mathbf{0 . 6 1 5}$ & 0.139 & 0.373 & $-\mathbf{0 . 5 3 8}$ & 0.019 & $-\mathbf{0 . 6 1 5}$ \\
$x_{50}$ & -0.148 & -0.120 & 0.243 & -0.351 & 0.002 & -0.508 & 0.021 & 0.311 & -0.142 & 0.333 & -0.337 \\
$x_{\max }$ & -0.204 & -0.126 & 0.093 & -0.310 & -0.010 & -0.425 & 0.033 & 0.377 & 0.004 & 0.432 & -0.135 \\
$x_{50} /$ FCO & -0.296 & -0.040 & 0.270 & -0.430 & 0.107 & $-\mathbf{0 . 6 3 6}$ & -0.266 & 0.354 & -0.406 & 0.374 & $\mathbf{- 0 . 6 4 2}$ \\
$50 / P($ FCO $)$ & -0.298 & -0.048 & 0.280 & -0.433 & 0.090 & $-\mathbf{0 . 6 3 9}$ & -0.259 & 0.365 & -0.430 & 0.334 & $-\mathbf{0 . 6 7 1}$ \\
FF-vol & $\mathbf{0 . 7 6 1}$ & -0.149 & 0.051 & 0.018 & -0.035 & 0.175 & $\mathbf{0 . 8 4 5}$ & -0.055 & 0.167 & 0.135 & 0.261 \\
FF-vol-FCO & $\mathbf{0 . 5 5 7}$ & 0.057 & -0.317 & 0.275 & -0.081 & 0.393 & 0.441 & -0.214 & 0.147 & -0.184 & 0.284 \\
FF-surf & $\mathbf{0 . 7 3 8}$ & 0.024 & -0.018 & 0.252 & 0.042 & 0.406 & $\mathbf{0 . 7 8 3}$ & -0.397 & 0.197 & -0.210 & 0.349 \\
\hline
\end{tabular}

Lognormal fits always predict a higher slope (all errors are positive), errors being smaller as the slope itself is higher and the higher the ratio of the median size to the FCO. These properties also apply, to a minor extent, to the Rosin-Rammler fits and are another way of looking at the failure of both functions to describe the fragment distribution below the FCO.

One more correlation analysis has been done, of the errors in the calculation of $s_{50}$ and the errors in the calculation of the sizes. The general rule is that the error in the slope at $x_{50}$ has a strong relation with the errors in the sizes below $x_{50}$, and little relation with the errors in the large sizes. When errors from all the calculations are entered, the correlation coefficients (Spearman) are $0.76-0.83$ for sizes $x_{10}-x_{40}$ and $0.34-0.006$ for sizes $x_{50}-x_{90}$. Similar behavior is replicated by each calculation method independently. The significant correlation coefficients are positive, as a positive 


\section{J. A. Sanchidrián et al.}

error in the slope (higher slope than the sieved distribution) means that the calculated curve dips towards the fines more than the sieved one, thereby predicting less fines and larger sizes for a given percentage passing (hence positive errors). This in principle (with a reverse relation) could apply for large sizes, and there is in effect some tendency to negative correlations at sizes greater than $x_{50}$, but the correlation coefficients are much smaller and most of them are non-significant at the $95 \%$ level. In reality, larger sizes are less influenced by the central slope because they are measured values and do not depend on an extrapolation function.

\section{Conclusions}

The accuracy of the measurement of fragment size distributions of rock by image analysis has been thoroughly studied. The analysis has been based on Split Desktop software operating in automatic mode with an additional manual correction focusing on the major delineation errors only. Results have been obtained both with the system calibrated for the fines using the actual sieved distributions, and with a constant fines factor of $100 \%$. Besides the ordinary Split operation, size distribution functions have been obtained by fitting Weibull-Rosin-Rammler, Swebrec and lognormal distributions to the calibrated results at sizes greater than or equal to the FCO in order to assess the capability of these functions to fit the distributions in the coarse range and to extrapolate in the fines region. Similar calculations have also been done using the raw surface count of fragments before the volume transformation is performed by the code.

The error in the estimation of sizes has been analyzed as a function of the percentage passing. Using the FCO and the image resolution as key sizes in the analysis, the range of sizes may be divided into optically coarse (sizes greater than the FCO), central (between the FCO and the image resolution) and fines (below the resolution). The errors in the determination of sizes increase from the optically coarse to the fines whatever the calculation method is. Prediction bands of such regressions have been used as estimations of the maximum errors that can be expected across the size range. Where there is the possibility to calibrate the image analysis system in the whole size span, the fragmentation results are quite accurate in the ordinary operational mode (named V2 in this work); the error in the size determination is less than $30 \%$ in the coarse and most of the central range, increasing only for the optical fine sizes. Calibration, however, may not be feasible in practice, as the fines correction factor may have a wide variation even for a given site, process and rock, depending on the topology of the material's surface from one photograph to another. Errors in the noncalibrated use of the system naturally depend on how far the constant fines factor used is from the actual optimum factor, with a maximum relative value similar to the variation of the fines factor. This warns about using fines correction factors obtained in one calibration test; such calibration may only be of real benefit if the fines factor happens to have a small range of variation.

The errors in the coarse range are generally below $30 \%$ for the methods of calculation tested, except the non-calibrated ones, for which errors may go up to $100 \%$ near the FCO. Surface methods are similar to their equivalent volume-based one in this range. In the central size range the errors expected are less than $40 \%$ only with the 
calculation method V2. Errors of V2-SW and S2 rise up to 80-90\% in the lower limit, and are higher for the other methods.

In the difficult optical fines range, where fragment sizes and percentages passing are all extrapolated values, the errors may be expected to be, in the best of the methods (V2), up to $85 \%$, around $100 \%$ for S2, and $125 \%$ for V2-SW and V1 - these errors may be higher at sizes smaller than the lower limit of our analysis, $r_{P}=0.151$. Such errors are actually large, but they tell that (i) the non-calibrated operation of Split can still predict the fines tail with a relatively limited error, or at least comparable to the best methods in this range; (ii) the Swebrec function appears to have a good ability to extrapolate the fines, especially when it is considered that the fitting is performed only on the sizes greater or equal the FCO; (iii) the surface calculation, with the fines factor adjusted to the FCO, is extrapolated towards the fines with relative success.

The comparison of methods V3 and S2 allows to conclude that surface calculations can characterize the fragment size distributions with errors not greater than what the volume calculations have when the criterion for adjustment of the fines correction factors are equivalent. This suggests that the fines correction applied to the surface size distribution is able to account, to some extent, for the volume transformation.

Weibull-Rosin-Rammler and lognormal distributions fitted to the material "seen" by the delineation system, even if properly calibrated sample by sample, are not appropriate for fitting fragment size distributions in the whole range of sizes. While the error is small at sizes greater than the FCO, the variability is always high and large individual errors may be expected even in the central range. Their performance is totally unacceptable in the fines.

In summary, the smaller expected errors (a measure of the accuracy) in the determination of the size distributions are those of the following methods of calculation (maximum relative errors are given):

(i) Optical coarse range: any calibrated method, $35 \%$.

(ii) Optical central range: V2, 40\%; V2-SW, 85\%; S2 and V1, 90\%.

(iii) Optical fine range: V2, 85\%; S2, $100 \%$.

\section{References}

Bond FC (1952) The third theory of comminution. Min Eng 4: 484-494

Chung SH, Katsabanis PD (2000) Fragmentation prediction using improved engineering formulae. Int J Blast Fragment 4(3-4): 198-207

Chung SH, Noy MJ (1996) Experience in fragmentation control. In: Franklin J, Katsabanis PD (eds) Measurement of blast fragmentation. Proc. 5th Fragblast Workshop on Measurement of Blast Fragmentation, Montreal, 23-24 August. Balkema, Rotterdam, pp 247-252

Cunningham CVB (1983) The Kuz-Ram model for prediction of fragmentation from blasting. In: Proc. 1st Int. Symposium on Rock Fragmentation by Blasting, Luleå, Sweden, 22-26 August. Luleå University of Technology, Luleå, pp 439-452

Cunningham CVB (1987) Fragmentation estimations and the Kuz-Ram model - four years on. In: Proc. 2nd Int. Symposium on Rock Fragmentation by Blasting, Keystone, Colorado, USA. Society for Experimental Mechanics, Bethel, CT, pp 475-487

Cunningham CVB (1996) Keynote address: optical fragmentation assessment - a technical challenge. In: Franklin J, Katsabanis PD (eds) Measurement of blast fragmentation. Proc. 5th Fragblast Workshop on Measurement of Blast Fragmentation, Montreal, 23-24 August. Balkema, Rotterdam, pp 13-19 
Girdner KK, Kemeny JM, Srikant A, McGill R (1996) The split system for analyzing the size distribution of fragmented rock. In: Franklin J, Katsabanis PD (eds) Measurement of blast fragmentation. Proc. 5th Fragblast Workshop on Measurement of Blast Fragmentation, Montreal, 23-24 August. Balkema, Rotterdam, pp 101-108

Kemeny J, Girdner K, Bobo T, Norton B (1999) Improvements for fragmentation measurement by digital imaging: accurate estimation of fines. Proc. 6th Int. Symposium on Rock Fragmentation by Blasting, Johannesburg, 8-12 August. The South African Institute of Mining and Metallurgy, Johannesburg, pp 103-109

Kou S, Rustan A (1993) Computerized design and result prediction of bench blasting. In: Rossmanith HP (ed) Proc. 4th Int. Symposium on Rock Fragmentation by Blasting, Vienna, 5-8 July. Balkema, Rotterdam, pp 263-271

Latham JP, Kemeny J, Maerz N, Noy M, Schleifer J, Tose S (2003) A blind comparison between results of four image analysis systems using a photo-library of piles of sieved fragments. Int $\mathbf{J}$ Blast Fragment 7(2): 105-132

Maerz NH (1996) Reconstructing 3-D block size distribution from 2-D measurements on sections. In: Franklin J, Katsabanis PD (eds) Measurement of blast fragmentation. Proc. 5th Fragblast Workshop on Measurement of Blast Fragmentation, Montreal, 23-24 August. Balkema, Rotterdam, pp 39-43

Maerz N, Zhou W (2000) Calibration of optical digital fragmentation measuring systems. Int J Blast Fragment 4(2): 126-138

Moser P (2003) Less fines production in aggregate and industrial minerals industry. In: Holmberg R (ed) Proc. 2nd World Conference on Explosives and Blasting, Prague, 10-12 September. Balkema, Rotterdam, pp 335-343

Ouchterlony F (2003a) Influence of blasting on the size distribution and properties of muckpile fragments, a state-of-the art review. MinFo Project P2000-10: energy optimisation in comminution. Luleå University of Technology, Swebrec, pp 81-95

Ouchterlony F (2003b) Bend it like Beckham or a wide-range yet simple fragment size distribution for blasted and crushed rock. Technical report No. 78, EU Project contract G1RD-CT-2000-00438. Swebrec, Stockholm

Ouchterlony F (2005a) The Swebrec ${ }^{\mathscr{C}}$ function: linking fragmentation by blasting and crushing. Inst Min Metall A 114: A29-A44

Ouchterlony F (2005b) What does the fragment size distribution of blasted rock look like? In: Holmberg R (ed) Proc. 3rd World Conference on Explosives and Blasting, Brighton, 13-16 September. European Federation of Explosives Engineers, Reading, UK, pp 189-199

Ouchterlony F, Niklasson B, Abrahamsson S (1990) Fragmentation monitoring of production blasts at MRICA. In: Proc. 3rd International Symposium on Rock Fragmentation by Blasting. The Australasian Institute of Mining and Metallurgy, Brisbane, Australia, pp 283-289

Ouchterlony F, Nyberg U, Olsson M, Bergqvist I, Granlund L, Grind H (2003) The energy balance of production blasts at Nordkalk's Klinthagen quarry. Proc. 2nd World Conference on Explosives and Blasting, Prague, 10-12 September. Balkema, Rotterdam, pp 193-203

Ouchterlony F, Nyberg U, Olsson M, Bergqvist I, Granlund L, Kontturi M (2004) The WP6 + 7 blasts at Nordkalk's Klinthagen quarry. Technical Report No. 93, EU Project contract G1RDCT-2000-00438. Swebrec, Stockholm, p 21

Sanchidrián JA, Segarra P, López LM (2006) A practical procedure for the measurement of fragmentation by blasting by image analysis. Rock Mech Rock Eng 39(4): 359-382

Segarra P, Sanchidrián JA, Moser P, Grasedieck A, Smöch B, Pascual JA (2005) Energycontrolled blasting for less fines production. In: Holmberg R (ed) Proc. 3rd World Conference on Explosives and Blasting, Brighton, 13-16 September. European Federation of Explosives Engineers, Reading, UK, pp 535-543

Split Engineering (2001) Split-desktop software manual. Split Engineering LLC, Tucson

Tessier B, Schleifer J, Grasedieck A, Sanchidrián JA, Ouchterlony F (2002) Description and documentation of the fragmentation and blast data system installed in the quarries. Technical Report no. 12, EU Project contract G1RD-CT-2000-00438. École National Supérieure des Mines, Paris 